Research Article

\title{
Antihypertensive drug use and blood pressure control among in-patients with hypertension in a Nigerian tertiary healthcare centre
}

\author{
Aduragbenro DA Adedapo ${ }^{1,3}$, Waheed Adeola Adedeji ${ }^{1,3}$, Abiola Muhammad Adeosun ${ }^{1,2} *$, \\ Japhet Olaremi ${ }^{1}$, Cecelia Kehinde Okunlola ${ }^{3}$
}

\author{
${ }^{1}$ Department of Pharmacology \\ and Therapeutics, University \\ of Ibadan, Ibadan, Nigeria \\ ${ }^{2}$ Department of Biochemistry, \\ Lead City University, Ibadan, \\ Oyo State, Nigeria \\ ${ }^{3}$ Clinical Pharmacology, \\ University College Hospital \\ Ibadan, Nigeria
}

Received: 02 February 2016

Revised: 15 March 2016

Accepted: 16 March 2016

*Correspondence to:

Dr. Abiola Muhammad

Adeosun,

Email: immunity11@gmail.com

Copyright: (c) the author(s), publisher and licensee Medip Academy. This is an openaccess article distributed under the terms of the Creative Commons Attribution NonCommercial License, which permits unrestricted noncommercial use, distribution, and reproduction in any medium, provided the original work is properly cited.

\begin{abstract}
Background: Hypertension is a risk factor for coronary heart disease, renal failure, stroke and death if not detected early and treated appropriately. Pattern of drug use provides information on quality of use by comparing the use of drugs with recommended guidelines. This study assessed the pattern of drug use and blood pressure (BP) control among in-patients with hypertension.

Methods: This was a retrospective study carried out on hospitalised patients with hypertension in a tertiary health care centre. Patients' demographic data, clinical findings, and prescription pattern were documented. The average of three consecutive blood pressure $(\mathrm{BP})$ readings prior to discharge was used to assess BP control.

Results: Of 162 patients, $27(16.7 \%)$ and $62(38.3 \%)$ patients were admitted with moderate and severe hypertension respectively. One hundred and fifty three $(94.4 \%)$ patients were on antihypertensive drugs, out of which 32 (20.9\%) had monotherapy, 62 (40.5\%) had two antihypertensive combinations, $59(38.6 \%)$ had three or more antihypertensive combinations. The order of antihypertensive drugs use was calcium channel blocker (CCBs) $114(70.4 \%)$, angiotensin converting enzyme inhibitors (ACEIs) 100 (61.7\%), diuretics $98(60.5 \%)$, centrally acting agent $24(14.8 \%)$, angiotensin receptor blockers (ARBs) 8 (4.9\%), and $\beta$-blockers (BB) 8 (4.9\%). Blood pressure control was achieved in $48.8 \%$ of the patients' population. Factors that negatively influence blood pressure control were presence of co-morbidity $(\mathrm{p}=0.027)$. Factor that positively influence blood pressure control was dietary lifestyle modification ( $\mathrm{p}=0.009)$.
\end{abstract}

Conclusions: The use of antihypertensive drugs was in accordance with treatment guidelines, but blood pressure was achieved in $48.8 \%$ of patients.

Keywords: Antihypertensive drugs, BP, Drug use, Hypertension

\section{INTRODUCTION}

Drug utilization studies are concerned with the marketing, distribution, prescription, dispensing and use of drugs in relation to the outcomes of use such as economic, social and clinical consequences. ${ }^{1,2}$ It is well known that, for drugs to produce desired therapeutic effects, they have to be safe, efficacious and be used rationally. Pattern of drug use provides information on extent of drug use, trend in drug use and quality of use (rational use pattern) by comparing the use of drugs with national and international guidelines, taking into account the clinical outcomes. ${ }^{1}$
Hypertension is a chronic medical condition that is most commonly seen in primary health care. ${ }^{3}$ In Nigeria, hypertension is the most common non-communicable disease and the most frequently diagnosed medical illness in elderly and senior executives. ${ }^{4,5}$ Management of hypertension is a key challenge to health care system; however, hypertension can be controlled by lifestyle modification or by the use of antihypertensive drugs or both. $^{6}$

Several guidelines, including the 2014 evidenced based JNC, emphasized lowering blood pressure in patients with hypertension to less than $140 / 90 \mathrm{mmHg}$ or lesser in 
some compelling indications, race or if tolerable. ${ }^{3,7,8}$ Clinical trials have shown the roles of antihypertensive drugs like diuretics (D), $\beta$-blockers (BB), calcium channel blockers (CCBs), angiotensin converting enzyme inhibitors (ACEIs), angiotensin receptor blockers (ARBs) and centrally acting agents (CAAs) in the reduction of hypertension related morbidity and mortality. ${ }^{8}$ Lowering blood pressure to acceptable level in patients often requires combination of two or more of these drugs. ${ }^{9}$ However, studies have reported low population of hypertensive patients having their blood pressure controlled. $^{10-12}$ In United States (US), Gu et al revealed that treatment of hypertension with the use of multiple antihypertensive drugs increased yearly and has contributed to decrease in morbidity and mortality caused by cardiovascular diseases, but adequate blood pressure control was achieved in less than $32 \%$ of these patients. ${ }^{10}$ Another study by Cheung et al reported an overall $41 \%$ blood pressure control in treated hypertensive patients despite increase in the use of antihypertensive combinations yearly among the Chinese. ${ }^{11}$ In one year study of hypertension among South African gold miners, substantial blood pressure control was achieved in $13 \%$ of these patients even with the use of more than one antihypertensive drug. ${ }^{12}$ Several studies in Nigeria have reported low blood pressure control among patients visiting the outpatient clinics in tertiary hospitals primary healthcare's, and in population where antihypertensive drugs were given free despite frequent use of antihypertensive combinations. ${ }^{13-15}$ Hospitalised patients are monitored by health care professionals, compliance is good and blood pressure control is expected to be better among them. This study retrospectively assessed drug use and blood pressure control among hospitalised hypertensive patients in a Nigerian teaching hospital.

\section{METHODS}

\section{Study design}

This study was a descriptive, cross-sectional, retrospective study on drug use among hospitalized patients with hypertension.

\section{Place of study}

The study was carried out at the University College Hospital (UCH), Ibadan, Oyo State, Nigeria.

\section{Sampling method}

One hundred and sixty-eight patients' case notes of patients with hypertension admitted within June, 2012 to July, 2013 were retrieved for the study using systematic stratified sampling method. Information collected from patients' case notes were entered into three sectioned questionnaire. The first section contained the sociodemographic information about patients, such as; age, sex, marital status, race, religion, weight, height, etc. The second section contained the clinical information about patients like; co-morbid conditions, family history of hypertension, laboratory biochemical results, length of hospitalization, daily blood pressure readings by physician from period admitted till when discharged. The third section contained information on drugs usage, such as drugs used before and while on admission. Patients discharged against medical advice, patients with incomplete medical records and patients that died while on admission were excluded from this study.

\section{Drug classification}

The anatomical therapeutic chemical classification (ATCC) system represents a common language for describing the drug assortment. ATCC was used for drug classification in this study. The ATCC for each drug was obtained from world health organization (WHO) guidelines for anatomical therapeutic chemical classification (ATCC) and defined daily dose (DDD) assignment, 2013. ${ }^{16}$

\section{Blood pressure categorization}

Patients' blood pressures on admission were classified according to world health organization-international society of hypertension (WHO/ISH) guidelines. ${ }^{17}$ The average of three consecutive blood pressure (BP) readings prior to discharge was taken as BP on discharge. Controlled blood pressure was taken as average BP on discharge $<140 / 90 \mathrm{~mm} \mathrm{Hg}{ }^{8}$

\section{Permission for the study}

Approval to carry out the study was obtained from the management of the University College Hospital and Head, Department of medicine, University College Hospital, Ibadan.

\section{Data analysis}

Statistical analysis was done using the statistical package for the social sciences (SPSS) version 16.0 software (SPSS Inc., Chicago, United States) and graph pad prism 6.0. Descriptive analyses were used for prevalence of parameters. Chi-square and cross-tabulation analyses were used to asses association between categorical variables $(P<0.05)$.

\section{RESULTS}

Of the 162 patients involved in the study, 88 (54.3\%) were male, while $74(45.7 \%)$ were female. Majority of the patients were in their middle age $78(48.2 \%)$ and mean age of the patients was 55.7 \pm 14.4 . Forty-five patients $(27.8 \%)$ patient were taking alcohol, smoking tobacco or both. Ninety seven patients $(59.9 \%)$ were obese. One hundred and five patients $(64.2 \%)$ completed tertiary education, and majority of the patients, 146 (90.2\%) were from Yoruba ethnic group. Further information on sociodemographic characteristics of the patients can be found on (Table 1). 
Table 1: Socio-demographic characteristics of hypertensive in-patients in a Nigerian tertiary healthcare centre.

\begin{tabular}{|ll|}
\hline Variables & \multicolumn{1}{l|}{ Frequency $(\%)$} \\
\hline Age & $36(22.2)$ \\
\hline $16-44$ & $78(48.2)$ \\
\hline $45-64$ & $48(29.6)$ \\
\hline$\geq 65$ & $74(45.7)$ \\
\hline Sex & $88(54.3)$ \\
\hline Females & \\
\hline Males & $116(71.6)$ \\
\hline Marital status & $31(19.1)$ \\
\hline Married & $10(3.1)$ \\
\hline Widow & $9(6.2)$ \\
\hline Divorced & \\
\hline Single & $104(64.2)$ \\
\hline Occupation & $30(18.5)$ \\
\hline Self employed & $28(17.3)$ \\
\hline Unemployed/retiree Civil & \\
\hline servant & $102(63)$ \\
\hline Religion & $60(37)$ \\
\hline Christian & \\
\hline Islam & $105(64.8)$ \\
\hline Education & $46(28.4)$ \\
\hline Tertiary & $11(6.8)$ \\
\hline Secondary & \\
\hline Primary & $146(90.2)$ \\
\hline Race & $14(8.6 \%)$ \\
\hline Yoruba & $2(1.2 \%)$ \\
\hline Igbo & $117(72.2)$ \\
\hline Hausa & $30(18.5)$ \\
\hline Alcohol and smoking & $11(6.8)$ \\
\hline Non-alcoholic non smokers & $4(2.5)$ \\
\hline Alcohol only & $97(59.9)$ \\
\hline Alcohol and smoking & $19(11.7)$ \\
\hline Smokes only & $46(28.4)$ \\
\hline BMI $*$ & \\
\hline Obese & \\
\hline Over weight & \\
\hline Normal & *lassification. ${ }^{18}$ \\
\hline BMI was classified based on WHO & \\
\hline & \\
\hline
\end{tabular}

Among these patients, diabetes mellitus was the most commonly diagnosed co-morbid condition. Further information on prevalence of co-morbid conditions among patients can be seen in (Figure 1).

On admission, 27 (16.7\%) patients were admitted with grade II hypertension while $62(38.27 \%)$ patients were admitted with grade III hypertension. Majority of the patients were on pharmacotherapy, $153(94.4 \%)$ while 9 $(5.6 \%)$ patients were not on any antihypertensive medication. Of those on pharmacotherapy, $32(19.8 \%)$ patients were on monotherapy, $62(38.3 \%)$ patients were on two antihypertensive combinations and $59(36.3 \%)$ were on three or more antihypertensive combinations. The prevalence of antihypertensive use in descending order are as follow: calcium channel blockers (CCBs)> angiotensin converting enzymes inhibitors > diuretics $>$ centrally acting methyldopa $>\beta$-blockers and angiotensin receptors blockers (Table 2 ).

Table 2: Clinical features and prevalence of drug use among hypertensive in-patients in a Nigerian tertiary healthcare centre.

\begin{tabular}{|ll|}
\hline Variables & Frequency (\%) \\
\hline BP on admission* & \\
\hline$<140 / 90$ & $32(19.8)$ \\
\hline $140-159 / 90-99$ & $41(25.3)$ \\
\hline $160-179 / 100-109$ & $27(16.7)$ \\
\hline$\geq 180 / 110$ & $62(38.27)$ \\
\hline BP on discharge** & \\
\hline$<140 / 90$ & $79(48.8)$ \\
\hline$\geq 140 / 90$ & $83(51.2)$ \\
\hline Antihypertensive used & \\
\hline ACEIs (C09AA) & $100(61.7)$ \\
\hline ARBs $(C 09 C A)$ & $8(4.9)$ \\
\hline BB (C07) & $8(4.9)$ \\
\hline CAA (C02) & $14(14.8)$ \\
\hline CCBs $(C 08)$ & $114(70.4)$ \\
\hline D $($ C03) & $98(60.5)$ \\
\hline Co-medications & \\
\hline Aspirin & $21(13.0)$ \\
\hline Heparin & $48(29.6)$ \\
\hline Insulin Therapy & $42(25.9)$ \\
\hline Coartem & $7(4.3)$ \\
\hline Metronidazole & $67(41.4)$ \\
\hline Augmentin & $40(24.7)$ \\
\hline Ceftriazole & $37(22.8)$ \\
\hline Blood pressure on of patents & \\
\hline
\end{tabular}

*Blood pressure on of patients admission was based on Hypertension classification by WHO/ISH guideline. ${ }^{17} * *$ Blood pressure of patients on discharge was marginalized into normotensive (controlled) $(<140 / 90)$ and hypertensive (uncontrolled) $(\geq 140 / 90) .{ }^{8}$ ACEIs-Angiotensin converting enzymes inhibitors; ARBs-angiotensin receptor blockers; CAAcentrally acting agent ( $\alpha$-methyldopa); CCBs-calcium channel blockers; D-diuretics.

Antibacterial were the most commonly used comedication. Of these, metronidazole, augmentin and ceftriazole were mostly used among these patients. Antimalarial was used by $7(4.3 \%)$ of the patients. Other commonly used drugs were insulin and heparin. Aspirin was found to be used by 21 (13\%) patients (Table 2 ).

Substantial blood pressure control (BP < 140/90 mm Hg) was achieved in $79(48.8 \%)$ patients. Factors that negatively influence blood pressure control were presence of co-morbidity $(\mathrm{p}=0.027)$. Factor that positively influence blood pressure control was dietary lifestyle modification $(\mathrm{p}=0.009)$. 


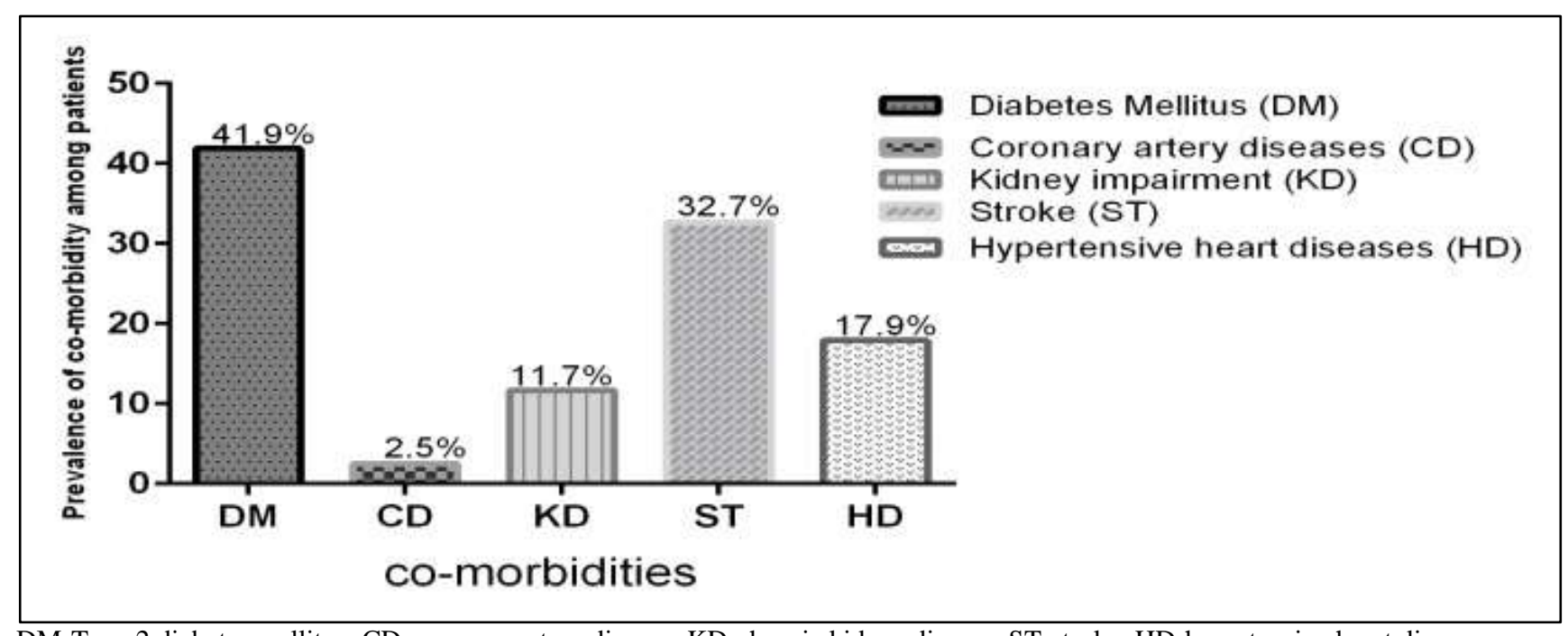

DM-Type 2 diabetes mellitus; CD-coronary artery disease; KD-chronic kidney disease; ST-stroke; HD-hypertensive heart disease.

Figure 1: Prevalence of co-morbidities among hospitalised hypertensive patients.

\section{DISCUSSION}

Data on drug utilization among hospitalized patients with hypertension in Nigeria are rare. In this view, these data are of importance with regards to the role of pharmacotherapy in the management of hypertension among patients on admission. This study assessed pattern of drug use and expressed the therapeutic outcome of drug use in terms of blood pressure control among hospitalized patients with hypertension. In general, the result of this study revealed that more than half of the hospitalized patients with hypertension had suboptimal blood pressure control despite been on combination therapy.

Many studies across the globe have reported similar case where minority had optimal blood pressure control, despite increase in the use of antihypertensive pharmacotherapy. An Irish survey found BP controlled in $48.6 \%$ of primary health care patients while study based on United States national health and nutrition examination survey (2001-2002) have reported BP control in 53.1\% of hypertensive patients. ${ }^{19-21}$

Majority of the patients were in their middle age. There were more male patients than female. Literature search shows that there was no consistency in gender distribution of patients with hypertension in Nigeria. Some studies reported higher percentage of males while some reported higher percentage of female patients with hypertension. $^{14,15,22,23}$ It has been reported that women visit hospital often, they have better treatment adherence and better utilization of health care services than men. ${ }^{24}$ Male preponderance among in-hospital patients with hypertension in this study may be because male patients do not visit clinic often until when they develop complication of hypertension, which may require hospital admission.
Diabetes mellitus, stroke, hypertensive heart diseases and renal failure were frequently co-diagnosed diseases. In conformity with several studies in Nigeria, diabetes mellitus has been the most prevalent ailment reported among hypertensive patients. ${ }^{13,14}$ The co-occurrence of these co-morbidities in hospitalized patients with hypertension will affect the choice of standard pharmacotherapy and achievement of substantial blood pressure control in these patients in line with international treatment guidelines. ${ }^{3}$

As previously reported in some studies on antihypertensive drug utilization pattern among patients visiting the outpatients' clinics in Nigeria, majority of the patients were on two or more antihypertensive drugs. ${ }^{14,22,25}$ Combination of antihypertensive drugs among hospitalized patients with hypertension was in line with recommendation of some studies which demonstrated that combination therapy is required in $70 \%$ cohort to achieve adequate reduction in blood pressure. ${ }^{8}$ The high prevalence of combination therapy usage can be attributed to higher population of patients admitted with moderate and severe hypertension, as well as co-existence of co-morbidities.

Angiotensin converting enzyme inhibitors (ACEIs) were the most commonly used drug as monotherapy. This is an indication that physician often use ACEIs as standard pharmacotherapy in many patients. Evidenced based guidelines buttressed the potentials of ACEIs, and CCBs among blacks and in compelling indication like diabetes mellitus, chronic kidney diseases and target organ damages. ${ }^{3,7}$ Higher frequency of ACEIs among patients on monotherapy may be cost related, or due to prevalence of diabetes among the patients.

The use of combination of ACE inhibitors and diuretics or calcium channel blocker have been shown to be beneficial 
in black hypertensive patients because combining any drug of these classes have produce significant reduction in blood pressure and mitigate of end-organ damage. ${ }^{26}$ Calcium channel blockers (CCBs), diuretics or ACEIs were more frequent in patients on two and three antihypertensive combinations. Several guidelines recommend the use of calcium channel blockers with diuretics in blacks and or with angiotensin converting enzyme inhibitors in the patients with compelling indication like diabetes and chronic kidney diseases. ${ }^{3,8}$ Patients taking four or more antihypertensive medication were mostly given centrally acting drug, methyldopa and/ or with $\beta$-blockers. Result from this study is an indication that antihypertensive prescription and utilization among in-patients was in accordance with recommended guidelines.

There was high prevalence of antihypertensive combination therapy usage among patients. Yet blood pressures remain suboptimal in more than half of the patients. Severity of blood pressure among hospitalized patients with hypertension seems to encourage physician to intensify treatment or substitute different antihypertensive classes. These patterns of antihypertensive combination use also conform to some studies. ${ }^{14,15,27,28}$ Higher mean blood pressure of patients on antihypertensive combination was reported in a study that compared blood pressure between patients taking monotherapy and those on combination therapies. ${ }^{28}$

Limitations of this study was due to retrospective nature of this study, some factors that may influence blood pressure control such as adverse reaction experienced, non-cardiovascular diseases, and surgical operation encountered by the patients were not recorded.

\section{CONCLUSION}

In conclusion, antihypertensive utilization conforms to recommended treatment guidelines for patients with hypertension, yet, the blood pressure control among was achieved in less than half of the hospitalized hypertensive patients' population.

\section{ACKNOWLEDGEMENTS}

The authors are grateful to Dr. Adebola E. Orimadegun, of the Institute of Child Health, College of Medicine, University of Ibadan for his statistical input. We also acknowledged the non-academic staff of the Clinical Pharmacology, University College Hospital, Ibadan.

Funding: No funding sources Conflict of interest: None declared

Ethical approval: Not required

\section{REFERENCES}

1. WHO. Introduction to drug utilization research. Geneva: WHO Collaborating Centre for Drug
Statistics Methodology, WHO Collaborating Centre for Drug Utilization Research and Clinical Pharmacological Services, 2003.

2. WHO. The selection of essential drugs. World Health Organization, 1977.

3. Himmelfarb CD, Handler J, Lackland DT, LeFevre ML, MacKenzie TD, Ogedegbe O, et al. Evidencebased guideline for the management of high blood pressure in adults report. From the panel members appointed to the eighth joint national committee (JNC8). JAMA. 2013;E1-E14.

4. Ogah OS, Okpechi I, Chukwuonye II, Akinyemi JO, Onwubere BJ, Falase AO, et al. Blood pressure, prevalence of hypertension and hypertension related complications in Nigerian Africans: A review. World journal of cardiology. 2006;4:327-40.

5. Ekere AU, Yellowe BE, Umune S. Mortality patterns in the accident and emergency department of an urban hospital in Nigeria. Nigerian Journal of Clinical Practice. 2005;8:14-8.

6. Becket NS, Peter R, Fletcher AE, Staessen JA, Liu L, Damitrascu D, et al. Treatment of hypertension in patients 80 years of age or older. N Eng J Med. 2008;358:1887-98.

7. Flack JM, Sica DA, Bakris G, Brown AL, Ferdinand $\mathrm{KC}$, Grimm RH, et al. Management of high blood pressure in blacks an update of the international society on hypertension in blacks (ISHIB) consensus statement. Hypertension. 2010;56:780-800.

8. Chobanian AV, Bakris GL, Black HR, Cushman WC, Green LA, Izzo JL, et al. The seventh report of the joint national committee on prevention, detection, evaluation, and treatment of high blood pressure: the JNC 7 report. JAMA. 2003;289:2560-71.

9. Yusuf S, Sleight P, Pogue J, Bosch J, Davies R, Dagenais G. Effects of an angiotensin-convertingenzyme inhibitor, ramipril, on cardiovascular events in high-risk patients. The heart outcomes prevention evaluation study investigators. The New England journal of medicine. 2000;342:145-53.

10. Gu Q, Ram RP, Dillon C, Vicki. Antihypertensive medication use among us adults with hypertension. Circulation. 2006;113:213-21.

11. Cheung BMY, Wong YL, Lau CP. Queen mary utilization of antihypertensive drugs study: use of antihypertensive drug classes in the hypertension clinic 1996-2004. B J clinical Pharmacol. 2005;60:90-7.

12. Maepe LM, Outhoff K. Hypertension in goldminers. SAMJ. 2012;102:30-3.

13. Tamuno I, Babahani M. Blood pressure control amongst hypertensive patients in a tertiary health care facility in Nothern Nigeria. Res J Med Sci. 2012;6:26-32.

14. Yusuff KB, Balogun O. Physician's prescribing of antihypertensive combinations in a tertiary care setting in southwestern Nigeria. J Pharm Pharm Sci. 2005;8:235-42. 
15. Salako BL, Ajose FA, Lawani E. Blood pressure control in a population where antihypertensives are given free. East Afr Med J. 2003;80:529-31.

16. WHO collaborating centre for drug statistics methodology: guidelines for ATC classification and DDD assignment 2014. Oslo. 2013.

17. WHO/ISH. 2003 world health organization (WHO)/international society of hypertension (ISH) statement on management of hypertension. Journal of Hypertension. 2003;21:1983-92.

18. WHO. Physical status: the use and interpretation of anthropometry. Report of a WHO expert committee. WHO technical report series 854. Geneva: world health organization. 1995.

19. Buckley B, Shanahan E, Colwell N, Turgonyi E, Bramlage P, Perry, IJ. Blood pressure control in hypertensive patients in Irish primary care practices. J Clin Hypertens. 2009;11:432-440.

20. Cheung BMY, Ong KL, Man YB, Lam KS, Lau CP. Prevalence, awareness, treatment, and control of hypertension. United States national health and nutrition examination survey 2001-2002. J Clin Hypertens. 2006;8:93-8.

21. Brewster LM, Van-Montfrans GA, Kleijnem J. Systematic review: antihypertensive drug therapy in black patients. Ann Intern Med. 2004;141:614-27.

22. Ukwe CV, Ubaka CM. Antihypertensive drug prescribing in a tertiary hospital in Eastern Nigeria.
Tropical Journal of Pharmaceutical Research. 2012;11:297-305.

23. Oyati AI, Orogade AA, Danbauchi SS, Azuh PC. Awareness, treatment and control of hypertension among hypertensives in Zaria. Journal of Medicine in the Tropics. 2011;13:139-44.

24. Steyn K, Bradshaw D, Norman R, Laubscher R. Determinants and treatment of hypertension in South Africans: the first demographic and health survey. S Afr Med J. 2008:98;376-80.

25. Isezuo AS, Njoku CH. Blood pressure control among hypertensives managed in a specialized health care setting in Nigeria. Afr J Med Med Sci. 2003;32:6570 .

26. Sica DA. The African American study of kidney disease and hypertension (AASK) trial: what more have we learned? J Clin Hypertens. 2003;5:159-67.

27. Adedapo ADA, Sikuade O, Adeleke S, Okechukwu R. Drug utilization and blood pressure control in a population where anti hypertensives are given free: effect of policy change. Afr J Med Sc. 2012;41:349-56

28. Etuk E, Isezuo SA, Chika A, Akuche J, Ali M. Prescription pattern of anti-hypertensive drugs in a tertiary health institution in Nigeria. Annals of African Medicine. 2008;7:128-32.

Cite this article as: Adedapo ADA, Adedeji WA, Adeosun AM, Olaremi J, Okunlola CK.

Antihypertensive drug use and blood pressure control among in-patients with hypertension in a Nigerian tertiary healthcare centre. Int J Basic Clin Pharmacol 2016;5:696-701. 